\title{
Service Quality in Alcohol Treatment: A Qualitative Study
}

\author{
Sheilagh M. Resnick • Mark D. Griffiths
}

Received: 26 February 2009 / Accepted: 24 April 2009

(C) Springer Science + Business Media, LLC 2009

\begin{abstract}
The objective of the study was to qualitatively evaluate the managerial and organisational issues associated with service quality in a privately funded alcohol treatment centre in the UK. Two different groups of participants at a private treatment clinic were interviewed. The first group comprised 25 of its patients. The second group comprised 15 staff members of the same clinic. All 40 interviews were transcribed and a thematic analysis was performed on the data to reveal the key themes. Six themes emerged from the interviews amongst patients and staff of the treatment clinic. The six themes were: (1) the fellowship of patients, (2) professionalism, (3) process and measurement, (4) incarceration, (5) empathy gap, and (6) access to treatment. Findings suggested there was a strong emphasis on management of the service delivery with established quality systems and performance measurement systems in place. The two service quality gaps, suggested by the research, were the rigid delivery of service and a lack of empathetic relationships with patients. Furthermore, by evaluating the service quality delivery from the service user's perspective, a voice was given to a group of patients, who in research terms have gone largely unheard.
\end{abstract}

Keywords Problem drinking · Addiction · Addiction services · Revolving door · Service quality

Service quality can be conceptualised as an evaluation or an attitude about a service offering or delivery but also viewed as an attribute that "closes the loop between evaluation and the choice process" (Bateson 1995; p.558). In the case of problem drinkers seeking treatment, the loop may be difficult to close because the number of services available makes it more complex. Many problem drinkers may not possess the physical and/or mental capacity to make appropriate choices (Edwards et al. 2003) and numerous choices of treatment services allows problem drinkers to move from one service to another and back again, creating a 'revolving door' practice. The 'revolving door' concept also shapes

S. M. Resnick ( $\bowtie) \cdot$ M. D. Griffiths

Business School, Nottingham Trent University, Burton Street, Nottingham NG1 4BU, UK

e-mail: sheilagh.resnick@ntu.ac.uk 
service expectations as many problem drinkers have experienced a number of treatment providers and this influences expectations of subsequent service providers. The literature suggests that in professional services, customers have 'fuzzy' expectations about what they expect from the service provider and are often unsure whether the service has met their expectations (Ojasalo 2001). To some extent, these 'fuzzy' expectations can be overcome by the relationship of the professional and the client (Stewart et al. 2000).

Healthcare in the UK is primarily delivered through the National Health Service (NHS) which was established in 1948 on the premise of "free and universal entitlement to Stateprovided medical care" (Klein 2006, p.1). Private sector healthcare accounts for around $17 \%$ of the total UK health expenditure (Laing and Buisson 2001) to which access is determined not by need but by the ability to pay. In recent years, there has been a decline of professional autonomy in the NHS due to the increase in the importance of managerialism coupled with tensions in the clinician/manager interface (Ferlie et al. 1996). Day and Klein (1987) suggest that because doctors are responsible for clinical resources and practice, they only regard accountability for quality delivery in terms of clinical outcomes and would only measure quality in this context (Morgan and Potter 1995). It could be argued however that clinical outcomes, quality systems, and processes are all intertwined and patients do not unravel one attribute from another when making judgments about the quality of service they receive.

More recently, the UK Government decided that "NHS patients should have more choice about care and treatment" (Baggott 2004; p.319). Patient choice was seen as a way of meeting some key performance targets by allowing people to be treated by private providers. It was also perceived that choice would be popular amongst patients, echoing an established consumer trend (Baggott 2004). However, assessing choice is healthcare is more complex than making choices about consumer services and having lots of choice may not improve health outcomes (Appleby and Dixon 2004).

In the UK, alcohol and drug treatment services are organised under the Mental Health National Service Framework (Department of Health 1998). There are extensive links between mental health problems and alcohol misuse, which has led to the term 'dual diagnosis', a term that can suggest that individuals suffer from "comorbid substance abuse as well as a psychotic, affective or severe personality disorder" (Evans and Sullivan 2001, p.1). Dual diagnosis affects the service funding and priority of treatment as there is a risk that patients with comorbidity fall between two service providers and health teams can receive insufficient expertise and training. In addition, alcohol and drug misuse services are often combined within the NHS and private sector clinics. A 10-year Government programme to combat drug misuse has resulted in drugs services receiving funding priority to the detriment of alcohol services. A study of alcohol treatment services in England revealed that $86 \%$ of service providers reported their alcohol treatment budgets being much lower than drug budgets (Department of Health 2005) and in this instance evidence-based practice in this context appears to have worked against alcohol treatment services.

Leatherman and Sutherland (2003) suggest that many who work in the NHS often view data with indifference, which may be rooted in concerns to protect professional autonomy. Additionally, data are not valued and they are perceived to be a means of satisfying Government requirements rather than as a tool to drive service quality. This results in poor data sets producing inaccurate performance measures and reinforcing the view that collecting data is not important. Although evidence suggests that progress in quality has been achieved for some parts of the NHS (Leatherman and Sutherland 2003) there has been no significant additional funding for alcohol services and quality systems. This raises the question whether service quality, as defined by the performance criteria of the NHS 'quality 
agenda' (Leatherman and Sutherland 2003) is relevant and appropriate to alcohol treatment services.

The organisation of alcohol treatment services is very fragmented. NHS specialist alcohol treatment units are organised to deal with complex cases of problem drinking and alcohol misuse. Brief interventions can take place in GP surgeries and hospital emergency departments and serious alcohol-induced liver disorders are treated in hospital departments. All of these NHS services are currently funded from primary care trusts (PCTs) whose purpose is to implement national health priorities where they are accountable to the Department of Health but they also have responsibility to plan and fund health services within the local community (Klein 2006). Voluntary alcohol treatment agencies, such as Alcoholics Anonymous (AA), provide services for a range of problem drinkers and receive funds from various sources such as local authorities, charities and the PCT (Touquet and Paton 2006). The PCT can also fund a level of patient care at private sector treatment facilities.

A study to assess national alcohol needs for England and Wales (Department of Health 2005) concluded that there was a large gap between the need for alcohol treatment and actual access to treatment. It was reported that only $6 \%$ of problem drinkers accessed specialist alcohol treatment and there was consensus that needs are not being currently met (Day, 2006). Only a third of all problem drinkers referred for specialist treatment actually accessed the service suggesting that there was potential to increase patient engagement with services.

In the home town of the authors (Nottingham, UK) there are around 23 alcohol treatment services but approaches can differ and services often compete rather than complement one another. The extensive choice of services in Nottingham has had almost a reverse effect by producing a 'revolving door' system that is not helpful to service providers, service users, or to taxpayers who fund services. There are also problems associated with the management of service quality because of the intangible nature of services. The nature of people with drinking problems presents significant challenges to service providers by their chaotic lifestyles, the complex nature of the condition and associated mental health problems. There are a number of different treatment philosophies and a wide choice of services within alcohol treatment. There is also the underlying issue of providing choice to patients who are not always capable of making good choices. Given all these complex but competing issues, the main objective of this study was to qualitatively evaluate the managerial and organisational issues associated with service quality in a privately funded alcohol treatment centre in the UK.

\section{Method}

Participants Two different groups of participants at the treatment clinic were interviewed. The first group comprised 25 of its patients. This group comprised of $64 \%$ males and $36 \%$ females with the average age of the group 43 years (see Table 1 for a breakdown of basic demographic information). Two-fifths of the patients $(40 \%)$ had been educated to degree level or above, with a further $16 \%$ having attended school or college to 18 years. Over half of the sample $(52 \%)$ comprised private patients and the remaining patients were funded by the NHS (48\%). The average length of stay was 17 days. Over $60 \%$ of the group had accessed other alcohol treatment facilities and of these, a quarter $(26 \%)$ had accessed the treatment clinic on a previous occasion. A quarter of the participants $(24 \%)$ were professionals as defined by their job, 35\% were in active employment and $8 \%$ were from the armed forces. 
Table 1 Basic Demographic Details of Patient Participants $(n=25)$

\begin{tabular}{lllll}
\hline Pseudonym & Age & Gender & NHS/Private & Other Services \\
\hline Sandra & 51 & F & NHS & Yes \\
Kelly & 32 & F & NHS & No \\
Joe & 30 & M & NHS & Yes \\
Frank & 50 & M & NHS & No \\
Margaret & 58 & F & NHS & Yes \\
Helen & 44 & F & NHS & No \\
Jenny & 41 & F & NHS & Yes \\
Wayne & 21 & M & Private & No \\
Linda & 47 & F & Private & No \\
Frances & 49 & F & Private & No \\
Michael & 44 & M & Private & Yes \\
Cathy & 52 & F & Private & Yes \\
Ian & 51 & M & Private & No \\
Malcolm & 56 & M & Private & Yes \\
Mark & 36 & M & NHS & Yes \\
Paul & 34 & M & Private & Yes \\
Jeremy & 41 & M & Private & Yes \\
Neil & 37 & M & NHS & Yes \\
Ed & 25 & M & NHS & Yes \\
Simon & 35 & M & Private & Yes \\
Sean & 30 & M & Private & No \\
Pete & 52 & M & Private & Yes \\
Teresa & 47 & M & NHS & Yes \\
John & 63 & NHS & No \\
Bill & 54 & Private & No \\
\hline & & & \\
\hline
\end{tabular}

The second participant group comprised 15 staff members of the treatment clinic. This group comprised $40 \%$ males and $60 \%$ females with the average length of time employed in the clinic 2.6 years. (see Table 2 for a breakdown of basic demographic factors). The staff sample reflected all the main roles within the treatment clinic of which there were five nurses, trained in both general and psychiatric nursing, two therapists, four administrative support staff, three domestic support staff, and a clinic director whose background was psychiatric nursing. Staff who declined to be interviewed included two therapists, a receptionist and two night time nurses. For the purposes of qualitative data reporting in this study, all participants were assigned pseudonyms (see Tables 1 and 2).

Background on the Treatment Clinic The treatment clinic was opened in 1990 and offers care and treatment (primarily) on an in-patient basis built around a 28-day programme. The clinic specialises in alcohol and drug dependency and has a standard programme of treatment based on the 12-Step philosophy. The programme involves a number of days in detoxification, progression to group work, visits to Alcohol Anonymous (AA) meetings, spoken and written accounts of life stories and reflective diary exercises. The programme is organised around group therapy rather than tailored to individual addictions. 
Table 2 Basic Demographic Details of Staff Participants $(n=15)$

\begin{tabular}{llll}
\hline Pseudonym & Gender & Length of employment & Worked in NHS \\
\hline Debs & F & 2.5 years & Yes \\
Bob & M & 2.5 years & Yes \\
Nancy & F & 2.4 years & No \\
Cheryl & F & 30 years & No \\
Dan & M & 20 years & Yes \\
Molly & F & 40 years & No \\
Ruth & F & 40 years & No \\
Phil & M & 10 years & Yes \\
James & M & 0.5 years & Yes \\
Paul & M & 2.5 years & Yes \\
Megan & F & 0.5 years & No \\
Carla & F & 60 years & No \\
Val & F & 2.5 years & Yes \\
Fred & M & 3.0 years & No \\
Carol & F & 2.5 years & Yes \\
\hline
\end{tabular}

Although the treatment clinic is an independent service provider, it has a contract with the Nottingham Primary Care Trust (PCT) for NHS funding for 7 of its 16 beds. The NHS beds are allocated to patients through general practitioners (GPs), who contact the treatment clinic recommending patient treatment. The NHS-funded patient undergoes a preassessment period of up to 6 weeks comprising a weekly meeting and three telephone contacts per week. Once patients have satisfied the pre-admission criteria they are transferred onto a waiting list (of 2-8 weeks). Patients can only be referred to the treatment clinic through PCT funding twice, and the treatment clinic must produce assessment and measurement information for the PCT. The Nottingham PCT has established a set of criteria for patients to be admitted to the treatment clinic. This provides clear guidelines for access to treatment, stringent pre-assessment procedures, limitations on access to treatment, and measurement of the service outcome. There are currently no formal criteria for access to NHS treatment services and no requirement to provide outcome or measurement information.

Procedure The first author approached the treatment clinic seeking permission to undertake research on service quality in that organisation. The study involved interviews with both patients and staff members of the treatment clinic. Posters advertising the research were displayed throughout the clinic and the first author attended a weekly after care group, which yielded additional participants. However, the main means of recruitment was through the head therapist approaching patients and asking for volunteers. For the staff members, the first author presented the objectives of the research to the clinic's management team and an e-mail was sent to all members of staff informing them of the study and inviting them to volunteer. Following participant recruitment, the first author interviewed participants in a private room in the organisation, recording the interviews. Two patient interviews were not analysed. This was because the participants were not able to sufficiently comprehend the process (possibly due to their recent detoxification treatment). 
Analysis All interviews were transcribed and a thematic analysis was performed on the data to reveal key themes that emerged. More specifically, transcripts were interpreted by adopting what Robson (2002) describes as an 'immersion' approach. This approach is characterised as being the "least structured and most interpretive, emphasising reader insight, intuition and creativity" (p.458). However, some elements of structure were adopted by use of coding and the identification of themes and patterns (see Appendix 1). It should also be noted that many questions were for the most part open in the hope that this would encourage participants to expand on the topic of service provision quality. An important part of the analytic process was the re-interpretation of the transcripts after identification of these themes. This facilitated a much deeper understanding of the participant conversations and helped construct a picture of how patients and staff evaluated service quality.

\section{Results}

\section{Emergent Themes}

Six themes emerged from the interviews amongst patients and staff of the Treatment clinic. These themes have been interpreted from the interviews from both patients and staff to both identify and contextualise the themes. The six themes were: (1) the fellowship of patients, (2) professionalism, (3) process and measurement, (4) incarceration, (5) empathy gap, and (6) access to treatment.

The Fellowship of Patients

An overriding theme, which emerged through patient interviews, was that their fellow patients contributed to service quality through their mutual support and sharing of problems and experiences. For instance, typical comments included:

"You can't do recovery on your own. You have to share in groups"(John)

"You form a band, talk about your drinking careers. You do not have to hold back as everyone has the same problem" (Frank)

"I do not always understand everything but the group help me out afterwards" (Neil)

"The relationship you build. It was surprising how close the patients become after a short space of time" (Wayne)

"The mix of people is the big part of it and what helps you afterwards. I use any excuse to come back as I have formed a fellowship with other patients" (Cathy)

The mechanism for this fellowship was the group therapy. For instance, Jeremy suggested that "[the clinic] delivers... a fellowship of men and women who share their experiences through [cognitive behavioural therapy]". Malcolm perceived that "all of us are in the same boat... they are part of my recovery and will help my recovery". Simon talked about how "nice it was to be in the group. Share thoughts and feelings" and Linda described the feeling as "bonding...people with similar interests".

The patients comprised of a broad mix of age, gender, education and social backgrounds and patients found this mix beneficial. Linda believed that she had her "eyes opened. Alcoholics sitting across from me, five girls in their twenties". John commented that "they are from all walks [of life]... that makes it better as you can see how destructive alcohol can 
be". Kelly believed that a "cross section of population helps. Makes you realise that alcoholism can affect anyone". Wayne spoke about "how lucky I have been as I have loving parents. Lots of people have had terrible things happen to them". However, the fellowship was not without its conflicts as commented by Kelly

"There are personality clashes...clashes with people of different duration. When it does happen you are encouraged to talk about it and get it sorted"

Frances had found it "difficult to work with some patients" and did not like "uncontrolled groups". A minority of patients did not relate to the group work. For instance, Sean suggested that "the groups do not work for me personally but I can see it does for others" Michael requested one-to-one therapy as "I could express feelings that I could not in a group".

Group therapy was perceived as being at the heart of the treatment programme and staff member Carol described the detoxification process as getting them "fit for therapy". The treatment programme actively encourages membership and fellowships of other groups (such as AA), and patients can access an aftercare group at the Treatment clinic on a weekly basis for up to a year. The literature suggests that service quality in professional services is delivered by the relationship between the service provider and the user (Stewart et al. 2000) but in the treatment clinic, the research here suggests that service quality is in some part created by the service users themselves. This may reflect the residential nature of the clinic in that patients form a bond from being physically together practically $24 \mathrm{~h}$ a day. However, it is likely that the fellowship of patients at this clinic is created through the professional approach of the clinic staff towards patients and the type of relationship they want to create with them as service providers.

\section{Professionalism}

When asked to describe how service quality is delivered at the clinic, many patients talked about expertise, training, structure and physical delivery of services and used the term 'professional' as a descriptor of these attributes. Paul talked about how the staff were "experts in what they are doing". Ed commented on the "skills of the staff". Bill suggested that "therapists were well trained". Pete talked about the staff being "very professional" and the "quality of staff and therapist being very good". Malcolm described the "medication as being well administered" and Helen perceived that she was receiving a "clear and structured programme". Joe described the staff as being "best in field... having knowledge in alcohol". Professionalism was also perceived in the sense of the physical attributes of the service such as the detox and the group therapy sessions. For Frank service quality in this context was "getting a detox so I can go into groups and find out why I drink".

When asked how they deliver service quality, the staff of the treatment clinic articulated this in concepts of training and knowledge and used the term 'professional' to describe themselves and this perception was supported by the patients. Kelly suggested that "staff were knowledgeable and well qualified". Margaret considered that the most important thing is "staff being trained" and Ian talked about the "professionalism of people who worked at the [treatment clinic]". Professionalism by this definition was having the "right type of qualifications, knowledge, specialists in their fields".

Staff member Carla discussed service quality as having "qualified individuals that can deal with patient problems" and professionalism for some staff was derived from "training and guidelines" (Phil). The key training programme was a computer-based programme that allowed members of staff to undertake the programme at their convenience and appropriate 
level. Cheryl described the treatment clinic as offering "exceptional access to training" with regular attendance on courses. In addition to work-based training, there were comprehensive guidelines that all members of the team had to comply with such as health and safety regulations, and criteria for working with vulnerable patients.

Although the patients of the treatment clinic appreciated the professionalism of the staff, it could be suggested that this approach, coupled with an emphasis on group rather than individual therapy, distances them from patients, prevents the development of one to one relationships and creates an empathy gap (discussed further below). The professionalism of the service was also linked to another theme-process and measurement.

\section{Processes and Measurement}

Service quality as a management philosophy is related to managing processes (Gronroos 1990) and the treatment clinic appeared to have an extensive management processes in place. The main processes that emerged in the interviews were (i) the 'pre-admissions process' for NHS-funded patients, (ii) the patient feedback process, (iii) processes for audit and monitoring of practices, and (iv) processes for measurement of patient treatment outcomes.

Pre-admission Process There were different admission systems for access into the treatment clinic reflecting whether the patient was private or NHS-funded. A private patient, as put explicitly by Jeremy, can access the treatment clinic merely by "getting your wallet out and paying. I am fortunate to be able to do that". This particular patient had arrived drunk and falling over but had to produce his credit card before staff would allow him in the door. For NHS patients there is a strict admissions process. For some patients, the pre-admission process was overly long and drawn out. Neil described pre-admission meetings as "boring." The same things are said every time. "I found it difficult to stay sober to attend the meetings". Mark described the process as "stringent...you have to prove your commitment". For Helen the pre-admission process resulted in waiting at least 10 weeks for treatment and as she stated:

"I needed the treatment now. [I] realise that private patients get priority but it was a very uncertain time not knowing whether I was coming or not"

The staff at the treatment clinic saw the pre-admission process as meeting the criteria established by the PCT and perceived that their waiting list for NHS patients was a 'healthy' one as suggested by Carla. "It's important for us to have the pre-admissions process as it proves motivation by the patient." Patients did not share the 'healthy' waiting list view. Jenny perceived that:

"The waiting list is too long. If you go privately, you are in within a few days but you can be waiting two months by the NHS and when you are desperate it's a long time"

The treatment clinic demarcated between private and NHS patients, reinforcing a hierarchy between patients. However, issues of motivation and commitment to the programme are equally relevant to private patients as they are to NHS-funded patients, and it would be logical and professionally ethical to extend the pre-admission process in some form to private patients.

Patient Feedback Patient feedback has formed an important part of the NHS quality agenda and the treatment clinic had a number of patient feedback processes in place. Each Friday, 
there is a community users group chaired by an ex-patient of the treatment clinic, who described her role as:

"From the service user perspective. I pass comments on and go to a clinical governance meeting and feed any comments through"

This group also involves staff such as the housekeeper and the chef for patients to feed back any domestic issues. Feedback worked both ways. Staff member Molly said "we tell patients if we have problems with them such as leaving clothes on the floor. This gives us a chance to air our gripes". There is also an exit questionnaire for patients, which they are encouraged to complete before departure. The findings are compiled on a quarterly basis and published on the staff intranet with all members of staff encouraged to access it. The questionnaire posed some problems for the less well-educated patients such as Ed who complained that "they expect you to know how to fill things in and I am not good with pen and paper". Neil also claimed that "I have problems with paperwork". The emphasis on process and paperwork was challenging for a number of patients and the first author often witnessed patients helping each other out on writing up life stories and with diary entries.

Audit and Monitoring Each year, the Healthcare Commission independently audits the treatment clinic and the most recent report suggested that the service was of a good standard. There are also a number of internal audit and monitoring systems in place. Staff member Ruth commented that "we are always monitoring things, looking at areas that work well and how can we do it better". Carla suggested that "patients were monitored very well in treatment". Val discussed the "audit tools [including] ...clinical governance [and] audit timetable" and Carol also talked about "policies and guidelines... reams of them".

Patients also perceived that the treatment clinic had audit and monitoring systems in place and for some patients this was an important signpost for delivery of service quality. Frances described what service quality involved for her as:

"Being interviewed, assessed and regularly reviewed to ensure I get the service I need and which suits me"

The annual audit by the Healthcare Commission appears to have a focus on standards and measurement in the treatment clinic and concentrated attention on improving standards on an ongoing basis.

Outcome Measurement Outcomes in alcohol treatment are not perceived to be easy to define or evaluate. The treatment clinic also recognises that there are difficulties in defining treatment success as articulated by Paul:

"What is success? Quality of life or sobriety? Stopping drinking often can be the only way but people can remain dependent on services around them and do not move on. They can be 15 years in recovery but have not recovered their lives and become addicted to the recovery"

This sentiment was also articulated by Dan who thought that any measurement of success should reflect quality of life as much as sobriety:

"People may go out and drink and could be OK. People may not be drinking but be miserable. For me it's about quality of life and what you achieve after the programme. Part of that goal could be sobriety" 
For Carol "every day without a drink is a victory" and this suggested that she measured success only in terms of sobriety. There are clearly difficulties in measuring outcomes from problem drinking (Raistrick et al. 2006) but the treatment clinic commissioned an in-depth survey from an external agency 10 years ago to try and establish a measurement system. This survey has not been continued and the treatment clinic currently has a system whereby they contact patients after three, six and twelve-month intervals and ask them (via telephone) questions around abstinence. Specific questions about quality of life are not asked, but some verbatim comments are captured. This research suggests there is an underlying negative aspect to the treatment clinic's process and measurement approach to patient care. This manifested itself in one of two themes: (1) feelings of being incarcerated within the treatment clinic; and (2) the lack of empathy from staff towards patients.

\section{Incarceration}

The theme of incarceration emerged from patients in connection with the lack of physical activities at the treatment clinic and with patients having to share a room with one another. Sharing a room for some patients triggered the sense that they were imprisoned or trapped within the clinic with little privacy in either a physical or a metaphysical way. A patient having his or her own room was also perceived as being in recognition of private patient status as opposed to being NHS-funded. There is a notion that this incarceration theme reflects the early church "sin" model for drinking. Just as penance was meted out by the church for drunkenness, the "penance" for the treatment clinic patients could be perceived as being the lack of recreation as epitomised by no gym facilities or not being able to go for a walk. Penance in the early church was also meted out reflecting the hierarchy in the church (Edwards et al. 2003), and in the treatment clinic this concept could be interpreted as the status of private patients being accorded a single room while the NHS patients (lower down the treatment clinic hierarchy) have to share. The theme of incarceration could also be interpreted as being imprisoned for the sin of drunkenness and some patients talked about this concept almost in those terms.

For instance, for Helen "there is no space to walk, no grounds...lack of physical facilities", for Ian "the free time is boring. The clinic needs exercise facilities as we are sitting down all day". Simon said "you need to exercise when you feel better. We are only allowed out to go to AA meetings". Jenny expressed it as "feeling claustrophobic. No facilities. Let you out for a walk on Christmas day". Ed perceived it as being "very shut in...[only] allowed to walk to shops in threes" and Joe articulated it as feeling "locked in at times. [We] cannot go out and [there is] no means of keeping fit. I am just smoking more". Cathy suggested that they were "only allowed out to go to AA meetings" whereas Kelly described the feeling in terms of:

\section{"Cabin fever. [A] feeling of isolation and you cannot go anyway. Feelings come back after drinking then you are stuck in one place with people you don't know"}

Sharing a room with another patient added to this sense of imprisonment. The treatment clinic has five single rooms, which are allocated to private patients. All NHS-funded patients were sharing rooms, which was a point of contention for both private and NHS patients. Mark (NHS) described being "[an] outdoor person. I don't like having to share a room". Jenny (NHS) perceived that "with people all the time and sharing a room, it hindered my progress". Linda (Private) saw the private room as part of her status as a private patient. "I was asked if I would share and I said 'no way'. I am paying privately for someone on the NHS". 
From the staff interviews, the theme of incarceration was articulated in different ways. Although some staff saw the need for sport and physical facilities, Bob said "we need more space. This is a small building and there is not space for relaxation". Dan said "people have to stay in the building...we need some sort of exercise routine". Other members of staff saw exercise as detrimental to the treatment programme. Carol perceived that a "gym [is] not practical. The reason they are here is not for activities". Val said "the focus is on the therapy. They don't have the time for other things".

Linked to sharing a room was the comfort of the room, which was particularly commented on by private patients who are paying around $£ 3,000$ per week for the treatment. Jeremy (Private) complained that "there are no phones and no room service". Malcolm (Private) suggested that "showers slow and erratic". Bill (Private) commented that "there were no locks on the door" and Linda (Private) thought that "room [is] OK. It's not the Ritz [hotel]". Pete (Private) suggested that his room "could be a bit warmer for $£ 3,000$ a week". Some members of staff suggested that the bedrooms should not be too comfortable with Phil suggesting that "patients moan about no TV in the bedroom but it's not about the bedroom but the quality of the programme delivered to them". Debs suggested that "we don't want patients in the bedrooms but taking part in the programme".

The theme of incarceration reflects the treatment philosophy of the religious model for alcohol, of undergoing penance for the sin of drunkenness, and a feeling of a retreat and removal from normal life so that the problem drinker can avoid the temptation of drink. The downside of this closed off world is that eventually patients have to return to the real world and do not always cope. Cathy sadly recounted that three months after leaving the clinic "I have relapsed. I did not want to leave here as I felt safe. Problems start again when I get home". Michael talked about "the benefits of the programme" but this was the second time this patient had been in the treatment clinic in 3 years. Jeremy, when asked why he had relapsed after receiving treatment from the treatment clinic and numerous other services commented that "it wasn't painful enough".

As part of the 12-Step philosophy, there is an emphasis on patients declaring themselves to be an 'alcoholic' and this declaration could be interpreted as a public repent. Margaret talked about the first meeting "when I had to say my name and state that I was an alcoholic was a shock. I had never said that before". Research into alcohol treatment by Raistrick et al. (2006) suggests that the most effective treatment is the one that the patient believes will work for them. For many patients in the treatment clinic the "disease" and "sin" model for alcohol treatment and the 12 Steps were perceived as powerful tools to help them recover from their problem drinking but linked to this theme was some element of an empathy gap within the treatment clinic.

\section{Empathy Gap}

Gummesson (1991) suggests service quality will only be delivered if commitment by the management and the staff is genuine. In healthcare, this can imply not only performing the service function competently, but also investing emotional ties to the service delivery, such as compassion, empathy and involvement in the provider-patient relationship. As mentioned above, patients in the treatment clinic articulated service quality around the concepts of 'fellowship of patients' and 'professionalism of staff' with some patients perceiving some lack of empathy from the staff. Jenny felt a "bullying culture" from a particular member of staff. Sean perceived that the treatment clinic had "petty rules...I can't have my own DVDs". Helen also felt that some of the staff were "bureaucratic. If you do not fill in forms on time you are not allowed family visits". 
The following commentary from Jenny articulates the feelings that problem drinkers can harbour about themselves:

"I realise that drug and alcohol users are treated badly. There is little compassion for users as it is seen as self-induced and that we are all liars. My father used to call drug users 'dirty junkies' but he is an alcoholic himself. We are discriminated against and it is seen as degrading and there is a stigma attached. If you go for help you expect to be treated like a child and you are lucky to get anything and you only get what you deserve"

This discourse reflects how this patient had lost her self-esteem and almost her identity through her problem drinking. She expects to be treated badly as this reinforces the low self-opinion she has of herself. It is suggested that patients such as Jenny would benefit from empathy and understanding as much as from a structured programme of recovery. This emphasis on keeping patients within the structure of the programme was articulated by certain members of staff such as Fred who said that:

"Patients are told what is happening...told if they break the rules they will be straight out the door. [They] need guidelines to bring them back on track"

Other members of the team observed these emotionally broken patients and witnessed the empathy gap in the clinic. Nancy articulated some of issues with the process that prevails at the treatment clinic, where emphasis is on group therapy:

"Some of the patients need more one-to-one. [It] doesn't happen any more. Some sit on their own for a few days, which is sad. They are upset and do not know anybody. [It] needs more attention on that"

Linked to this was a comment from Carla who suggested that there:

"Is too much focus on getting the paperwork done and the care bit gets pushed aside. Not much gets done about it"

Cheryl was more forthright on this topic suggesting that "patients are not always spoken to in the right way. Compassion is not always shown". Phil believed that people get "bogged down in paperwork and do not always remember to put the patient first".

\section{Access to Treatment}

The final theme, which emerged from both patients and staff, was the challenge of accessing treatment for problem drinking. There is a very large gap between the provision of alcohol treatment and need or demand with perceived difficulties in accessing specialist treatment because of waiting lists (Department of Health 2005). Three main issues, in relation to accessing alcohol treatment and articulated by patients and staff of the treatment clinic were the (i) role of general practitioners (GPs) in identification and referral of drinking problems, (ii) experience of other treatment services and (iii) wide choice of treatment services.

General Practitioners GPs are often the first port of call for problem drinking but a general practice research data base identified low levels of formal identification, treatment and referral of patients with alcohol use disorders by GPs (DOH 2005). John perceived that too often they have "no obvious understanding of addiction and just said don't drink rather 
than trying to understand why you are drinking”. Some patients had to change GPs in order to get help as illustrated by Malcolm

"I changed to a GP who was younger and more aware of alcohol problems. [He] did a complete health check and gave me details of APAS, AA and NHS community service"

Margaret reported that her GP just said "try not to drink" and this patient perceived that "it's is a disease, which [GPS] don't understand and they have got people with bigger issues". Bill reported that his doctor "just advised me to cut down drinking. [He was] not knowledgeable about drinking and did not understand". Michael was a GP himself and he admitted that:

'Looking back, my own training was in inadequate and even 'tiny'. I had a leaflet about the places available but it was a lottery as to where I sent people. I knew nothing about places such as AA"

From the staff perspective, Megan perceived that "GPs are under pressure. I think they need help with signposting of agencies". Val perceived that "there is a vital role in getting treatment for patients....the fluctuation between GPs is immense". However, Carol perceived that GPs were "getting better and there are pockets where GPs have a special interest in alcohol".

The treatment clinic has implemented an active communication programme for Nottingham GPs with the employment of a member of staff to visit GPs surgeries and by holding GP seminars at the clinic. GP referrals account for $24 \%$ of all referrals to alcohol agencies (DOH 2005) but many patients were critical of the approach taken by some GPs. Sandra perceived herself to be a "revolving door. I have got to go somewhere. [My] GP referred me eventually". Joe had been referred by his GP to the "[Local alcohol advisory service] where I had an interview and was promised a key worker but nothing happened."

The referral by GPs onto other services in Nottingham, including the treatment clinic, was somewhat of a lottery, with some GPs clearly knowledgeable about the treatment clinic facility and others not. For patients outside Nottingham, a further issue emerged that although the Nottingham PCT fund seven beds at the treatment clinic, other PCTs do not have this facility either because the beds and/or the funding are not available. For two patients who lived in neighbouring counties, this was articulated as healthcare by "postcode lottery". Malcolm confirmed that he "wrote to my MP...[that alcohol treatment] is [a] postcode lottery. I was told they are cutting beds [locally] and moving to care in the community". Bill confirmed that he went back to his GP who said treatment was a "postcode lottery" and that the locality had "no funding for this type of treatment". Jeremy said that there was "only one bed in [in the whole county] for detox".

Although GPs were criticised by many patients there were equally some patients who viewed their GPs positively for both the identification and referral of their drinking problem and in their willingness to refer them to the treatment clinic. Ed said his GP "was great, understanding...told me I had a long life ahead of me and referred me here". Mark explained that he "went to GP and told him the situation. He wrote a letter to the treatment clinic who accepted me for pre-assessment". Teresa considered her GP to be "very knowledgeable and knew about the treatment clinic... [he] tried to match my problem with the treatment". Some patients had gone to their GP with the specific aim of referral to the treatment clinic through NHS funding. Mark confirmed that the treatment clinic had been "mentioned to me by a Counsellor who recommended it so I told the GP". Helen a well 
educated former medical doctor, who had researched her options, remarked that "I wanted to get here and my GP agreed to refer me". Frank remarked that there had been "no problem getting here through the NHS".

Over half the NHS patients in the treatment clinic had received a good education and it would appear that the referral system is patient-led rather than GP recommended. The referral process also raises the issue of why GPs should be referring to private healthcare providers without a first referral to NHS services. Both these issues underline the lack of training and knowledge that GPs have in alcohol treatment.

Experience of Other Alcohol Treatment Services Of the 15 patients who had accessed other treatment services, nine patients had experienced the NHS controlled drinking treatment programme in either Nottingham or another city. Many of these patients reported failure with controlled drinking. Neil went to "the NHS clinic controlled drinking but ended up drinking more. [I] tried to cut down but found it impossible". Ed had also been to "the NHS but did not believe controlled drinking was feasible for him". Margaret had been assigned a key worker in the NHS but "saw her only four times a month and needed more time". Cathy had been under a nearby county NHS service for 3 years but "it did not work".

For many patients, abstinence was the only way in which they perceived they could control their drinking. Michael had been referred to the NHS but felt "abstinence was the way for me". Frank believed that "controlled drinking was not helping" and Sandra went as far as to suggest that "controlled drinking is killing people". Frances suggested that "if it's not abstinence then it's not a proper treatment programme". Some patients had accessed AA and struggled to adapt to its ethos. Neil had been to AA meetings but ended up sitting next to a "nutter who sent me a text saying 'God will help you'". Cathy ended up next to a "lesbian in the AA meeting who took me for a drink afterwards". John acknowledged that "AA can be seen as a religious cult" but other patients had found a lot of support from AA after leaving the treatment clinic. Helen spoke about "meeting people at AA who you can relate to" and Jeremy compared the concept of the fellowship of patients to "AA. Lots of people go for years".

\section{Choice of Treatment Services}

The different alcohol treatment approaches on offer in Nottingham leads onto the aspect of choice and competition within these services. Dan saw the choice on offer in Nottingham as "overwhelming. Patients don't know where to go". Paul perceived that having choice was fine as long as:

"Choice options give a clear idea of what the service is going to provide. Choice within different levels is debatable and it is questionable whether you need ten services for counselling. When an individual decides to do something about their problem then treatment needs to be available. Access becomes more important than choice"

Because there are no systems to monitor patient flow from one service to the next, patients have to undergo a full assessment every time they access a new provider, which not only creates duplication of paperwork and effort but also demotivates patients. Megan observed that "they drop out and then try to pick up again but face yet another assessment, which is a bad experience". Paul observed that there was a "wealth of services in Nottingham and at times duplication". This member of staff also observed that there was "so much money coming into drugs and alcohol that services can see it and can see a pot of money coming their way". Although this member of the team perceived that numbers of 
services were (in one sense) healthy, he also articulated the revolving door scenario that went hand-in-hand with choice of service provision:

"I may go to one service and don't like it, and then go onto the next one. It's a revolving door spinning people from one service to the next. Five services are being funded by the PCT in Nottingham and one patient could be getting five services. The system is untracked and un-audited"

The sheer numbers of services in Nottingham has given rise to competition for funding as explained by Dan:

"There is competition amongst providers for funding which had led to an unhealthy relationship, especially in the voluntary sector. I was surprised how polarised the services were. We have developed good links with organisations that can interface us...We get some - but not many-referrals from the NHS alcohol services."

Competition between services spilled over into differences in treatment philosophy as explained by Paul who perceived that there was a "massive difference of opinion between harm-reduction and heavily-dependent end. 12-Steppers tend to be reformed 12-Steppers". There is a service users forum in Nottingham. This forum had identified the need for a common assessment tool for problem drinkers and an effective signposting system for referring people onto the most appropriate service, but (to date) had no concrete plans in place. As Paul remarked:

"There are too many services, and if you had a clean sheet of paper you would not have all these services. [We] need to develop services which are required and the current diversity of services reflects individual approaches. You need a central UK wide approach, funding needs to be questioned and need to ask where this service fits in"

There are a number of issues surrounding the provision of alcohol treatment services in Nottingham and it could appear that the level of service choice currently available is neither helpful nor cost-effective for service providers as it creates the revolving door practice already discussed in this paper. The research here at the treatment clinic identified a number of themes, which influenced the delivery of service quality.

\section{Discussion}

A number of clear themes influencing service quality emerged from this study. An overarching theme throughout this research was the differing interpretation of what service quality means to the different stakeholders (i.e., patients versus staff). Sutherland and Dawson (1998) suggest that quality is a contested issue with individuals within the NHS delivering the concept according to their judgment of it. The clinic's abstinence-based treatment programme had a defined set of processes, systems and outcomes, which has produced service provision based around 'hard' attributes of process, professionalism and profit. Patients expressed service quality expectations of achieving sobriety, recovery, and receiving a professional service. The clinic appears to deliver service quality to many of the specifications of the NHS quality agenda in terms of evaluation capabilities and performance measures, and this raises the question of accountability for service quality.

The research suggests that the clinic exerts professional, economic and political accountability. The clinical director of the clinic is accountable to a number of stakeholders; the owners of the clinic to deliver a profitable service, to the Healthcare Commission for 
maintaining appropriate professional standards, and to the PCT for delivering a service to a set of criteria and within an agreed cost. The clinic also engages in continual improvement of services, understands the notion of competition and the marketplace, has introduced initiatives to drive business and hold a long-term vision for the business.

In the clinic, where the PCT funds around $50 \%$ of their beds, there is potential funding vulnerability as continued funding of the NHS beds is key to the maintenance and growth of the treatment clinic's business. At a national level, Alcohol Concern (2007) identified under-funding across all alcohol services. Furthermore, a UK Government survey suggested that $86 \%$ of service providers reported their budgets lower on alcohol compared to drugs (DOH 2005). However, an issue that emerged from the study is how effective the current funding arrangements are as there is a wide choice of services within alcohol treatment in Nottingham, which creates competition for funding and a 'revolving door' practice and it could be argued that there is too much choice and inappropriate funding of services.

The concept of choice emerged at many levels in this study. The specific choice of treatment can shape service expectation in that patients of the treatment perceived that an abstinence approach met their expectations of the service more closely, particularly in the short-term. Patients cannot drink at all in the private treatment clinic and this alone means the treatment programme is constructed to meet patient expectations of the service for at least 28 days. The controlled drinking approaches that are offered in other NHS services may not produce short-term outcomes as this is a longer-term approach, which seeks to change individual behaviour towards drinking. There is no evidence to suggest that either abstinence or controlled drinking leads to better recovery from problem drinking (Raistrick et al. 2006) but differing treatment approaches have spawned a series of different service providers, which have created the 'revolving door' for problem drinkers to spin from one provider to another.

It could perhaps be argued that people often become problem drinkers because of the bad choices they have made in their lives and providing the current level of choice in treatment services in Nottingham is not helpful to either the service providers or users. Many problem drinkers also suffer from mental disorders as a result of their problem drinking or drink because of their poor mental health and offering choices of treatment services can confound treatment engagement. Choice also appears to dilute service quality as funding is spread thinly across a number of providers allowing clients to access multiple services. The revolving door of alcohol treatment services has emerged partly as a result of inadequate processes and measurement in the service provision as responsibility for the services is fragmented with no single body or authority with either the power or the purse strings to effect or organise change.

Shortcomings on process and measurement of alcohol treatment services occur at a national and local level. There are also a number of inconsistent practices and systems across the whole treatment arena. The PCT have established a stringent set of criteria for NHS patient access to the private treatment clinic yet there are no such criteria for entry to NHS services. The private clinic implements strict criteria for treatment for NHS patients yet have no criteria for private patients other than the ability to pay. There are no defined pathways for GP referral onto any tier of alcohol treatment services and no monitoring or a database of problem drinkers from one service to the next.

The objectives of the study were to evaluate the managerial and organisational issues associated with service quality in private alcohol treatment. Findings suggest that there were very few managerial or organisational issues associated with service quality delivery. There was a strong emphasis on management of the service delivery with established quality systems and performance measurement systems in place. The two service quality 
gaps, suggested by the research, are the rigid delivery of service and a lack of empathetic relationships with patients. The research suggests that the clinic is delivering service quality in a way envisaged by the NHS quality agenda with an emphasis on performance improvement and capacity indicators. However, the research also suggests that this is being achieved at the expense of an empathetic relationship with patients with limited focus on meeting their individual needs.

There has been little if any research to date on the service quality delivery of alcohol treatment services from the perspective of the service user. There is a notion that this dearth of research may reflect the methodological difficulties associated with conducting research amongst this particular group, namely reliability of data from respondents with long-term drinking problems and related poor mental health. There is also the issue of subjectivity in perceptions based research and the difficulties in establishing independent objective measures. This research study focused on evaluating the service quality delivery from the service user's perspective and through this study a voice was given to a group of patients, who in research terms have gone largely unheard.

The extensive choice of alcohol treatment services in Nottingham and client ability to access these services also contributes to shortfalls in service quality as it creates a 'revolving door' that is not helpful to patients or service providers. The research suggests that this revolving door has evolved as a result of inadequate processes and measurement in the whole Nottingham alcohol treatment service provision with process faults emerging from the lack of the GP gatekeeper role and a lack of systems to monitor and measure client process through the different services. The conclusions drawn from this study are backed up in the wider literature on alcohol treatment services with the service provision deemed patchy with very few shared objectives or performance indicators and little capacity to tackle problem related drinking coherently (Prime Minister's Strategy Unit 2004).

This study was limited to one private sector alcohol treatment clinic in one city, Nottingham, which may not be a typical location in terms of service provision for alcohol treatment and it would be beneficial to undertake this study in another city to compare service delivery in another alcohol treatment service in either the private or public sector. Despite the increasing numbers of people suffering from problem drinking in the UK and the growing cost to the NHS of treatment and care of alcohol related illnesses, service quality delivery in alcohol treatment services is not widely researched. As a development of this research, future studies need to be undertaken, which would benefit from participation by a sample of GPs whose role as gatekeeper to specialist treatment services was discussed as part of this research. In addition, a review of local alcohol services and of the system for the commissioning of treatment services could start to manage the closing of the 'revolving door' of alcohol services.

\section{Appendix 1: Topic Guides for Participant Interviews on Whether the Treatment Clinic Delivers a Quality Service to Patients}

- What does a quality service mean to you?

- What do you think are the criteria for a quality service in the clinic?

- Who do you think decides whether the service is good or not?

- Who do you think judges whether a good service has been delivered?

- Are systems in place to deliver a quality service? What are these?

- Are practices in place to deliver a quality service? What are these?

- What are the gaps in the service provision? 
- Who is important in the service delivery process?

- What do you think about the service overall?

\section{References}

Alcohol Concern (2007). Safe. Sensible. Social. The next steps in the National Alcohol Strategy. A response from Alcohol Concern. Available at http://alcoholconcern.org.uk/servlets/doc/1195 (Accessed June 20th 2007).

Appleby, J., \& Dixon, J. (2004). Patient choice in the NHS. BMJ, 329, 61-62. doi:10.1136/bmj.329.7457.61.

Baggott, R. (2004). Health and health care in Britain (3rd ed.). Basingstoke: Palgrave MacMillan.

Bateson, J. E. G. (1995). Managing services marketing. Text and readings (3rd ed.). New York: The Dryden.

Day, M. (2006). NHS faces job cuts as financial crisis deepens. BMJ, 332, 743. doi:10.1136/ bmj.332.7544.743.

Day, P., \& Klein, R. (1987). Accountabilities: five public services. London: Tavistock.

Department of Health (1998). Mental Health National Service Framework. (online). Available at http://www. dh.gov.uk/en/PublicationsandStatistics/lettersand circulars/LocalAuthorityCirculars/AllLocalAuthority/ DH-4004760 (last accessed April 6 2009).

Department of Health (2005). Alcohol Needs Assessment Project. Available at http://www.dh.gov.uk/ en/Publicationsandstatistics/Publications/PublicationspolicyAndGuidance/DH-412234 (last accessed April 6 2009).

Edwards, G., Marshall, E. J., \& Cook, C. C. H. (2003). The treatment of drinking problems (4th ed.). Cambridge: Cambridge University Press.

Evans, K., \& Sullivan, J. M. (2001). Dual diagnosis. Counselling the mentally Ill substance abuser (2nd ed.). New York: The Guildford.

Ferlie, E., Ashburner, L., Fitzgerald, L., \& Pettigrew, A. M. (1996). The new public management in action. Oxford: Oxford University Press.

Gronroos, C. (1990). Service management: a management focus for service competition. J Serv Mark, 1(1), 6-14.

Gummesson, E. (1991). Truths and myths in service quality. Int J Serv Ind Manage, 2(3), 17-16. doi:10.1108/09564239110007256.

Klein, R. (2006). The new politics of the NHS. From creation to reinvention (5th ed.). Abingdon: Radcliffe.

Laing and Buisson. (2001). Laing's healthcare market review 2001/2002. London: Laing and Buisson.

Leatherman, S., \& Sutherland, K. (2003). The quest for quality in the NHS. London: The Stationery Office.

Morgan, P., \& Potter, C. (1995). Professional cultures and paradigms of quality in health care. In L. Kirkpatrick \& M. M. Lucio (Eds.), The politics of quality in the public sector. New York: Routledge.

Ojasalo, J. (2001). Managing customer services expectations in professional services. Managing Serv Qual, 11, 200-212. doi:10.1108/09604520110391379.

Prime Minister's Strategy Unit. (2004). Alcohol harm reduction strategy for England. London: Cabinet Office.

Raistrick, D., Heather, N., Godfrey, C. (2006). Review of the effectiveness of treatment for alcohol problems. Available at: http://www.nta.nhs.uk/publications/documents/nta_review_of_the_effectiveness_of_ treatment problems fullreport 2006 alcohol (last accessed April 6 2009).

Robson, C. (2002). Real world research (2nd ed.). Oxford: Blackwell.

Stewart, H. M., Hope, C. A., \& Muhlemann, A. P. (2000). Service quality in the legal profession; a review. Int J Manag Rev, 2(3), 261-286. doi:10.1111/1468-2370.00041.

Sutherland, K., \& Dawson, S. (1998). Power and quality improvement in the new NHS: the roles of doctors and managers. Qual Health Care, 7, 16-23.

Touquet, R., \& Paton, A. (2006). Tackling alcohol misuse at the front line. BMJ, 333, 510-511. doi:10.1136/ bmj.38961.556470.BE. 